\title{
A análise documentária no grupo Temma: dos indícios às evidências da formação de unidades discursivas"
}

Edivanio Duarte de Souza

Doutorando em ciência da informação pela Escola de Ciência da Informação da Universidade Federal de Minas Gerais.

E-mail: edivanioduarte@cci.ufal.br

\section{Dalgiza Oliveira}

Doutoranda e mestre em ciência da informação pela Escola de Ciência da Informação da Universidade Federal de Minas Gerais.

E-mail: dalandrade@yahoo.com.br

\section{Resumo}

O artigo busca entender a formação de unidades discursivas da análise documentária, no âmbito do Grupo Temma da ECA (Escola de Comunicação e Artes), da USP (Universidade de São Paulo), a partir da confluência teóricometodológica entre a bibliometria e a arqueologia do saber de Michel Foucault. Tem como objeto de análise empírica a coletânea "Análise Documentária: a análise da síntese," publicada em 1987 por este grupo. A pesquisa empírica foi realizada a partir de uma fase exploratória e outra focalizada. Define como categoria de análise as unidades paratextuais e textuais. Apresenta indícios e evidências que facultam várias considerações sobre as formações de unidades do discurso da análise documentária no Brasil.

\section{Palavras-chave}

Análise Documentária. Arqueologia do saber. Bibliometria.

The documentary analysis in the group Temma: from indications to evidences of the formation of discursive units

\begin{abstract}
The article poses the formation of discursive units in the documentary analysis in relation to the Group Temma from ECA (School of Communication and Arts) of USP (University of São Paulo) based on the theoristmethodological confluence between the bibliometry and the Archaeology of knowledge by Michel Foucault. It considers as the object of analysis the collection "Documentary Analysis: an analysis of the synthesis" published in 1987 by this group. The empiric research was based on an exploratory stage and another focalized. It defines as category of analysis of the paratext and text units. It also presents some evidences that show many considerations towards the formations of units of the documentary analysis discourse, in Brazil.
\end{abstract}

\section{Keywords}

Documentary analysis. Archaeology of knowledge. Bibliometry.

\author{
INTRODUÇÃO
}

A ciência da informação, com seu projeto interdisciplinar, tem possibilitado o desenvolvimento de estudos e pesquisas fundamentados em abordagens teóricometodológicas convergentes, notadamente aquelas que potencializam o entendimento e a possível resolução de problemas relacionados ao tão propalado caos documental. Essa área de estudo compreende, entre outras temáticas, a produção e a comunicação científica, que necessitam de todo o processo de tratamento e organização da informação materializada nos diversos suportes.

Nesse campo, a análise documentária se apresenta como uma das principais subáreas da ciência da informação que precisa dessas abordagens, uma vez que se dedica à complexidade do estudo dessa materialização da produção científica, a fim de analisar e descrever os conteúdos dos diversos tipos de documentos e, a partir desses processos, construir representações que se constituam em pontos de acesso - a saber, índices e resumos para posterior recuperação desses conteúdos (LARA, 2001). Esse projeto envolve uma série de esforços com direcionamentos a interlocuções entre diversas áreas, tais como a lingüística, a lógica, a inteligência artificial e a comunicação.

Pautados nesse entendimento, pesquisadores da ECA (Escola de Comunicação e Artes) da USP (Universidade de São Paulo) fundaram, no ano de 1986, o Grupo Temma, então constituído pelos seguintes professores: Anna Maria Marques Cintra, Eunides A. do Vale, Isabel M. R. Ferrin Cunha, Johanna Wilhelmina Smit, Maria de Fátima Gonçalves. M. Tálamo, Nair Yumiko Kobashi e Regina Keiko Obata F. Amaro**. Desde a sua criação até a atualidade, esse grupo vem desenvolvendo vários

\footnotetext{
* Artigo originário de discussões e trabalhos desenvolvidos na disciplina Arqueologia do Saber e Bibliometria do Programa de Pós-graduação em Ciência da Informação da Escola de Ciência da Informação da Universidade Federal de Minas Gerais.

** Atualmente, o Grupo Temma é composto pelos seguintes pesquisadores: Ana Maria Marques Cintra, João Batista Ernesto de Moraes, Johanna Wilhelmina Smit (líder), José Augusto Chaves Guimarães (lider), Maria de Fátima Gonçalves Tálamo, Mariângela Spotti Fujita, Marilda Lopes Ginez de Lara, Nair Yumiko Kobashi e Vânia Mara Alves Lima (BRASIL, 2007).
} 
estudos e pesquisas que resultaram em importante produção científica na área da análise documentária, conforme se pode observar em Oliveira (2005).

Dentre o universo dessa produção, destaca-se a coletânea "Análise Documentária: a análise da síntese" publicada, sob a coordenação da pesquisadora Johanna V. Smit, no ano de 1987, com financiamento do Ministério de Ciência e Tecnologia (Mct), Conselho Nacional de Desenvolvimento Científico e Tecnológico (CNPq) e do Instituto Brasileiro de Informação em Ciência e Tecnologia (Ibict). Essa publicação se apresenta com grande relevância por representar os primeiros fundamentos da construção de unidades discursivas nesta área, no Brasil, e resultar de esforços conjuntos de vários pesquisadores, apresentando-se, portanto, como materialização de parcela da produção desse grupo.

Nesse sentido, Smit (1987) afirma que a coletânea é resultante das muitas discussões acerca de temáticas relacionadas à "análise documentária", que decorrem, sobretudo, da implantação da linha de pesquisa do então Curso de Pós-graduação em Biblioteconomia da ECA/ USP. Aquele cenário contribuiu com o surgimento de preocupações convergentes e, conseqüentemente, com o desenvolvimento de estudos e pesquisas norteados por esta confluência com proposta interdisciplinar fundamentada na interlocução entre as áreas da documentação e da lingüística.

Assim, o trabalho coordenado por Smit (1987) permite um estudo preliminar sobre a formação do campo discursivo da análise documentária, no Grupo Temma, a partir da confluência entre essas duas áreas que se encontram ligadas diretamente à produção e à comunicação científica. Acrescente-se a isso que, conforme entendeu Lara (2001), compreendese que os processos de análise documentária e construção de linguagens documentárias se assemelham ao processo de construção de conhecimento, uma vez que ambos utilizam analogias e generalizações nos atos de representação.

Dessa forma, o presente artigo objetiva compreender essa formação de unidades discursivas a partir dos indicadores bibliométricos paratextuais e textuais da referida publicação. Ademais, propõe evidenciar pontos que estejam ligados à bibliometria e que possibilitem a construção de indicadores de qualidade científica. Para tanto, conceitua-se a bibliometria no campo da ciência da informação, apontando os métodos utilizados na definição dos indicadores. Ao mesmo tempo, busca evidenciar os indícios da formação do discurso da análise documentária tomando como parâmetro traços característicos dos enunciados apontados por Michel Foucault (2000) em sua obra Arqueologia do Saber.

Essa abordagem teórico-metodológica possibilita a ampliação dos indicadores bibliométrico e a construção de indicadores qualitativos a partir de uma rede complexa de interdiscursividade presente, sobretudo, nos estudos de citação.

\section{BIBLIOMETRIA E CONSTRUÇÃO DE INDICADORES DE PRODUÇÃO CIENTÍFICA}

A segunda metade do século passado foi marcada pelo aumento exponencial de produção e consumo de informação, que caracterizou o conhecido "boom bibliográfico”. A partir daí, houve um chamamento, principalmente da sociedade científica, no sentido de planejar, organizar e disponibilizar essa crescente massa documental. Pode-se dizer que o fenômeno informacional passou a ser considerado um tema central nas discussões em várias áreas do conhecimento, notadamente, naquelas diretamente relacionada à produção e comunicação científica, como biblioteconomia e ciência da informação.

Surgiu, nesse contexto, maior preocupação com a qualidade da produção científica e tecnológica e, com ela, o desenvolvimento de metodologias para estudar o comportamento e os indicadores dessa produção como forma de embasar o desenvolvimento de políticas científicas, nos diversos campos do saber. A biblioteconomia e a ciência da informação, em particular, têm buscado, atualmente, intensificar o desenvolvimento de estudos, modelos e teorias que fundamentam todo esse processo, que visa avaliar a qualidade de publicações científicas com a finalidade de emitir a certificação de mérito.

A bibliometria, como subcampo da ciência da informação, tem como objetivo o estudo dos aspectos quantitativos da produção, disseminação e uso da informação registrada, a fim de oferecer subsídios a tomadas de decisão (MACIAS-CHAPULA, 1998). E, dessa maneira, compreende o levantamento de um conjunto de indicadores que, "além de auxiliar o entendimento da dinâmica da ciência e tecnologia $(\mathrm{C} \& \mathrm{~T})$, funciona como instrumento para o planejamento de políticas e tomadas de decisões neste setor" (SANTOS, 2003, p. 23).

Assim, em uma visão ampla, pode-se dizer que, ao mesmo tempo que se insere nos debates sobre o avanço da C\&T, insere-se no âmbito do progresso econômico e social (BORDONS; ZULUETA, 1999). E, para tanto, 
fundamenta-se em algumas premissas indispensáveis à compreensão do desenvolvimento da produção científica que, em síntese, destacam:

a) o progresso se dá em função da produção dos cientistas;

b) a construção dessa produção é pautada em precursores da área;

c) os resultados desses trabalhos são publicados e submetidos aos pares;

d) a literatura científica se apresenta como uma representação da atividade cientifica e da rede de relações entre os campos de conhecimento;

e) o número de publicações de um grupo de pesquisa pode representar um indicador de sua produtividade;

f) as citações feitas na produção se apresentam como indicador de impacto de determinada publicação (ROUSSEAU, 1998).

Dentre esses elementos apontados por Rousseau (1998), o fator impacto se apresenta como o que melhor expressa a qualidade e, portanto, possibilita a certificação de uma publicação. Além de configurar como uma síntese de uma série de outros elementos, já que se dá a partir do processo de citação, ele se apresenta como o indicador mais utilizado na atualidade para avaliar a qualidade de publicações científicas, de pesquisadores e/ou instituições de pesquisa.

Nas palavras de Campos (2003), ao avaliar a qualidade científica de determinada publicação, a premissa básica concerne ao entendimento de que a informação científica relevante corresponde àquela que serve como referência a outros trabalhos subseqüentes. Dessa forma, se um determinado periódico científico publica um trabalho que é referenciado por outros, isso implica que este, bem como a revista que o publicou, causou impacto na comunidade científica. Acrescente-se às suas características metodológicas que o fator impacto é um indicador bibliométrico patenteado pelo Institute for Scientific Information (ISI), o que, de alguma forma, tem lhe conferido selo de qualidade perante a comunidade científica.

Em uma visão mais metodológica, a bibliometria corresponde a uma ferramenta empírica utilizada no estudo e análise de documentos, a fim de mapear e gerar diferentes indicadores de tratamento e gestão da informação e do conhecimento em sistemas de informação e de comunicação científicos e tecnológicos, e de produtividade, necessários ao planejamento, à avaliação e à gestão da ciência e tecnologia de uma determinada comunidade científica ou de um país (BORDONS; ZULUETA, 1999; GUEDES; BORSCHIVER, 2005).
De acordo com Vanti (2002, p. 155), a bibliometria, a cienciometria e a informetria possibilitam, dentro de suas áreas específicas de atuação, algumas aplicabilidades, dentre as quais se destacam:

- identificar as tendências e o crescimento do conhecimento de uma área;

- identificar as revistas do núcleo de uma disciplina; mensurar a cobertura das revistas secundárias;

- identificar os usuários de uma disciplina;

- prever as tendências de uma publicação;

- estudar a dispersão e a obsolescência da literatura científica;

- prever a produtividade de autores individuais, organizações e países;

- medir o grau e padrões de colaboração entre autores;

- analisar os processos de citação e co-citação.

É preciso frisar que, apesar de sua abrangência conceitual e metodológica, há uma série de críticas aos estudos bibliométricos, sobretudo, pelo seu caráter eminentemente quantitativo. De acordo com Macias-Chapula (1998, p. 137), há inclusive muitos países que têm resistência em aceitar essas medidas, uma vez que há "alguns pesquisadores que rejeitam a idéia de ter sua atividade científica avaliada por um sistema quantitativo". Contudo, outros pesquisadores entendem a importância dessas informações para a orientação e a dinâmica das políticas científica e tecnológica de seus países. Nesse sentido, Alvarenga (1998, p. 254) compreende que "[...] o potencial gerado pela bibliometria se apresenta como insumos valiosos para o desenvolvimento de estudos arqueológicos e epistemológicos regionais, ou seja, dos campos específicos do saber". Acrescentando, a autora esclarece ainda que:

elementos textuais, paratextuais e contextuais referentes a monografias e artigos de periódicos se constituem em variáveis comumente abordadas nos estudos bibliométricos. Os resultados alcançados refletem aspectos quantitativos de campos do conhecimento, evidenciando ângulos, tais como produtividade de autores que constituem as frentes de pesquisa em determinado campo de conhecimento e constatações de regularidade que podem fazer emergir fatos históricos, no processo de evolução de uma disciplina (ALVARENGA, 1998, p. 254).

Assim, ao mesmo tempo que os estudos bibliométricos se dedicam a alguns elementos que definem um fator de impacto, possibilitam também a definição de uma série de indícios característicos da produção científica estudada, evidenciando o que Foucault (2000) denominou de superfícies de emergência do discurso. Esses 
elementos evidenciam, para além dos aspectos quantitativos, as relações interdiscursivas entre os enunciados que compõem a formação discursiva de uma determinada área do conhecimento.

\section{DA BIBLIOMETRIA À ARQUEOLOGIA DO SABER: PARA ALÉM DOS INDICADORES QUANTITAVOS}

Antes de qualquer consideração sobre a formação do discurso científico, faz-se necessário esclarecer que o entendimento deste em sua diversidade tipológica é aqui compreendido à luz do conceito de formação discursiva de Foucault (2000), ou seja, o discurso enquanto prática, que vai além dos parâmetros de cientificidade apontados pela ciência moderna, colocando-se no campo mais amplo do saber.

Ademais, é condição preliminar entender que, mesmo se dedicando aos indícios de formação do discurso científico, essa discussão se insere no âmbito da Arqueologia do Saber de Foucault, por considerar que suas análises arqueológicas podem se dedicar tanto a textos não-científicos, quanto a textos científicos.

O discurso científico retrata um conjunto de elementos que condiciona sua prática. Dessa forma, deve ser visto a partir de suas condições de produção. Além das variáveis históricas e geográficas, existe uma série de outros elementos que compõem um jogo de relações entre enunciados que Foucault (2000) denominou de formação discursiva.

Para Foucault (2000), essa rede de relações se apresenta a partir de uma dispersão de enunciados, em detrimento de uma ordem ou unidade do discurso propriamente dita, e se caracteriza pela forma como são construídos os objetos do discurso. De acordo com o autor, essas regras imprimem: a) a demarcação das superfícies primeiras de emergência, que significa fazê-lo aparecer, torná-lo nomeável e descritível; b) a descrição das instâncias de delimitação, que abrange os campos institucionais e as várias disciplinas que a envolvem; c) análise das grades de especificação, que compreende, no nível macro, o conjunto de relações possíveis.

Essas relações que se estabelecem entre os enunciados compõem as formações discursivas que evidenciam três traços característicos dos enunciados apontados por Foucault (2000): a raridade, a exterioridade e o acúmulo. Compreende-se que esses traços se apresentam como elementos fundantes da confluência entre as análises arqueológicas e as descrições bibliométricas. Ao mesmo tempo, pode-se verificar, tanto no âmbito teórico quanto no campo empírico, esses traços na produção técnicocientífica. Assim, as análises arqueológicas permitem ir dos indícios identificados por meio dos indicadores bibliométricos às evidências construídas pelos estudos e análises do jogo de relações entre esses indícios.

De acordo com o autor, a análise enunciativa deve considerar a raridade, que impõe a locação da análise do discurso sob o duplo signo da totalidade e da pletora, que, nas suas palavras:

mostra-se como os diferentes textos de que tratamos remetem uns aos outros, se organizam em uma figura única, entram em convergência com instituições e práticas, e carregam significações que podem ser comuns a toda uma época. Cada elemento considerado é recebido como a expressão de uma totalidade à qual pertence e o ultrapassa. Substitui, assim, a diversidade das coisas ditas por uma espécie de grande texto uniforme, ainda jamais articulado e que, pela primeira vez, traz à luz o que homens haviam "querido dizer", não apenas em suas palavras e seus textos, seus discursos e seus escritos, mas nas instituições, práticas, técnicas e objetos que produzem (FOUCAULT, 2000, p. 137, grifo do autor).

Essa noção de raridade explica o interdiscurso existente na prática discursiva. No campo da produção científica,

“[...] a publicação é o resultado de uma comunicação entre a razão individual e a coletiva. Assim, os pesquisadores, para consolidar suas argumentações, fazem referências aos trabalhos dos outros pesquisadores, que constituem, com esse arranjo, um certo consenso na comunidade científica" (SANTOS, 2003, p. 29).

Pode-se dizer, tanto a partir de Foucault (2000) - campo da análise arqueológica -,quanto de Santos (2003) espaço das descrições bibliométricas -, que o discurso se apresenta como pluralidade de sentidos, pletora de significado em relação a um significante único, sendo, portanto, ao mesmo tempo, plenitude e riqueza indefinida (FOUCAULT, 2000).

O outro traço característico a que Foucault (2000) se refere, a exterioridade do enunciado, tem como fundamento a retomada de enunciados conservados ao longo do tempo e dispersos no espaço. Assim, "o que importa é reencontrar o exterior onde se repartem, em sua relativa raridade, em sua vizinhança lacunar, em seu 
espaço aberto, os acontecimentos enunciativos" (FOUCAULT, 2000, p. 141).

Essa rede de relações fundamenta o entendimento de Santos (2003) de que "[...] existe uma relação entre todos os trabalhos científicos publicados, não sendo possível, no entanto, precisar o tipo de relação: se direta ou indireta, reconhecida ou dissimulada, consciente ou inconsciente, acordada ou não".

Em um pensamento convergente com o de Santos (2003), Foucault (2000) destaca a dificuldade metodológica em definir as precedências e a originalidade de enunciados nos níveis da seqüência e da semelhança. No que se refere àquela, Foucault (2000) esclarece que, mesmo considerando a definição de uma grande série única de enunciados, com marcos cronológicos homogêneos, não se pode definir que a precedência de um enunciado se constitua em medida precisa para distinguir o original do repetitivo. Da mesma forma, no que se refere a esta, esclarece que o fato de dois enunciados serem exatamente iguais não autoriza que esses sejam identificados de forma absoluta. Não há, portanto, semelhança necessária e imediatamente reconhecível entre formulações; essas relações são evidenciadas em um campo de jogo de formações discursivas.

O terceiro e último traço característico apresentado por Foucault (2000) corresponde ao tratamento dos enunciados na densidade do acúmulo que são considerados e que não deixam de modificar, de inquietar, de agitar e, às vezes, de arruinar. Trata-se, pois, de descrever o conjunto de enunciados como figura lacunar e retalhado, na dispersão de uma exterioridade, estabelecendo a positividade do discurso.

No entendimento do discurso científico, especificamente dos procedimentos adotados na construção dos referenciais teóricos de um campo do conhecimento, a noção de enunciação e de seus traços característicos apresentados em Foucault (2000) traz à luz uma série de referências a estudos e conceitos aplicados à bibliometria e observáveis no comportamento dos pesquisadores no momento da materialização de suas pesquisas, apontados por Guedes e Borschiver (2005): frente de pesquisa e colégios invisíveis; fator de imediatismo e de impacto; acoplamento bibliográfico e co-citação, entre outros. $O$ ponto de intersecção entre esses estudos e conceitos se dá no procedimento adotado, uma vez que todos eles têm como foco de estudo a análise de citação, evidenciando as diversas relações entre os enunciados.
Nota-se que, em caminho inverso, a partir da arqueologia do saber, os indicadores bibliométricos podem ser entendidos, sobretudo, como indicadores relacionais que funcionam como indícios e, muitas vezes, como evidência de uma rede complexa de interdiscursividade que se estabelece entre diversas ordens de discursos, permitindo ligações e comparações no âmbito do dito e do jamais dito, como esclareceu Foucault (2000).

Alvarenga (1998, p. 254) entende, por essa ótica, que:

por privilegiar os discursos publicados, os resultados de estudos bibliométricos no que tange especialmente à quantificação da literatura publicada e ao mapeamento das relações estabelecidas entre autores e textos, por meio das citações, podem se constituir em insumos empíricos da maior importância para que se evidenciem ângulos peculiares do processo de produção de conhecimentos, ensejando o desenvolvimento de posteriores análises qualitativas.

No que concerne aos procedimentos adotados nos estudos bibliográficos, Santos (2003) esclarece que se faz necessário o desenvolvimento de sistemas automatizados de informação científica e técnica para produção de indicadores, no entanto existem duas bases que não necessitam de manipulação prévia: a Web of Science e a World Patent Index. Além dessas fontes, em geral, não terem sido construídas para a produção de indicadores, em muitos países, grande parte da produção científica se encontra em formato impresso, tornando-se indispensável reformatar campos para a importação de dados e até mesmo construção de novas bases de dados.

\section{DAS DEFINIÇÕES E DA ORGANIZAÇÃO DO CORPUS ANALÍTICO}

A seleção do corpus analítico se deu a partir de algumas variáveis que contemplam o objetivo final do estudo, tais como uma produção científica, materializada e organizada de forma a possibilitar o estudo, considerando os dois postulados de Solla Price (1965) que explicam o comportamento do pesquisador no processo de produção científica, no âmbito individual e em frente de seus pares. Trata-se, pois, da construção de indicadores bibliométricos da coletânea Análise Documentária: a análise da sintese, e das relações que podem ser estabelecidas a partir desses indicadores. A obra é constituída de uma introdução e de sete capítulos, sendo que o último apresenta uma síntese da biografia dos autores e das obras dos referenciais adotados, não se constituindo em objeto de análises bibliométricas, neste artigo. Entretanto, esse capítulo foi fundamental 
no entendimento da constituição das evidências da formação das unidades discursivas.

Assim, considera o entendimento de Santos (2003, p. 31) que, com base em Callon, Courtial e Penna (1993), afirma: "Os métodos empregados buscam representar os elementos segundo cálculos de 'distância' que deverão estimar graus de 'semelhança' ou de 'dessemelhança' entre os elementos”. Essa postura faculta a confluência metodológica entre as abordagens quantitativa e qualitativa possibilitada pela bibliometria e arqueologia do saber.

As categorias de análise empírica dos indicadores bibliométricos do livro foram selecionadas com base nos elementos que influenciam o fator de impacto, uma vez que este se apresenta como principal índice bibliométrico utilizado na avaliação da qualidade da produção científica. De acordo com Campos (2003), as principais variáveis que influenciam o fator de impacto são as áreas de pesquisa, o tipo de revista científica, a periodicidade, o número de autores e o idioma.

Segundo os critérios de Campos (2003) e considerando que o objeto empírico corresponde ao conjunto de referências e citações utilizadas na composição de uma coletânea, foram definidas as seguintes unidades de análises paratextuais - fonte de informação, idioma, período de publicação, autoria e temáticas referenciadas - e textuais citação e temáticas abordadas. As temáticas referenciadas foram estabelecidas a partir dos títulos e subtítulos das fontes de informação referenciadas, e as temáticas abordadas, por sua vez, correspondem aos títulos dos capítulos e dos subcapítulos da obra analisada.

Em função de os dados paratextuais e textuais do livro em análise não se encontrarem em uma base de dado automatizada, a pesquisa empírica se deu em duas etapas: uma exploratória e outra focalizada. A primeira teve como objetivo identificar todos os elementos que se constituem em categoria de análise para este estudo com a finalidade de construção de uma base de dados secundária que possibilitou a manipulação dos dados, conforme sugestão de Santos (2003). A segunda se referiu à manipulação dos dados de acordo com a necessidade de produção de indicadores bibliométricos a partir da massa considerável de dados identificados e coletados na fase anterior.

No que diz respeito à análise dos dados gerados, o confronto, a comparação e a análise desses elementos possibilitaram a construção de indícios e evidências que permitiram a interpretação e o entendimento dos indicadores bibliométricos. Para tanto, os elementos paratextuais foram considerados a partir da análise de freqüência, enquanto que os elementos textuais, além dos aspectos quantitativos, foram organizados de forma a demonstrar as relações semânticas e hierárquicas, considerando os princípios básicos do Sistema de Classificação Decimal de Dewey.

É necessário destacar também que os dados empíricos coletados permitem o estabelecimento de uma série de outras relações que vão além das aqui empreendidas.

\section{DOS INDÍCIOS ÀS EVIDÊNCIAS DO DISCURSO DA ANÁLISE DOCUMENTÁRIA NO GRUPO TEMMA}

A análise e a discussão dos resultados aqui empreendidas partem da noção de que o conjunto de relações estabelecidas entre os indicadores bibliométricos paratextuais permitem a definição de alguns elementos que contribuem com o entendimento dos aspectos textuais e do campo discursivo do objeto analisado como um todo. A primeira observação que deve ser feita diz respeito aos fundamentos de formalização da formação discursiva, ou seja, a rede interdiscursiva que o discurso analisado constrói com discursos anteriores a partir dos enunciados das fontes referenciadas.

A coletânea foi escrita fazendo referência a um universo de 54 (cinqüenta e quatro) documentos, sendo que desse total 7 (sete) se apresentam como co-referência, demonstrando o efetivo interdiscurso entre as construções dos discursos dos próprio autores. Essa prática é caracterizada por Foucault (2000) como definição de regularidades discursivas no processo de formação. É importante também destacar que essas co-referenciações se deram a partir de 6 (seis) fontes de informação, sendo que uma delas foi referenciada por 3 (três) autores.

A referência a trabalhos anteriores evidencia uma afiliação, embora que parcial, a esses discursos, possibilitando inferir, a partir do entendimento de Campos (2003), a importância e qualidade destes na construção do discurso da análise documentária. A co-referenciação, por sua vez, reforça essas inferências, demonstrando as efetivas correlações entre as unidades discursivas.

Com relação à tipologia das fontes de informação utilizadas, pode-se considerar inicialmente que todas elas se constituem em publicações formais. E, conforme a tabela 1, a seguir, o maior percentual de fontes de informação referenciadas compreende artigos de 
TABELA 1

Tipologia dos documentos

\begin{tabular}{|c|c|c|}
\hline Descrição & $\mathbf{f}(\mathbf{x})$ & $(\%)$ \\
\hline Artigo de Periódico & 14 & 29,79 \\
\hline Capítulo de Livro & 07 & 14,89 \\
\hline Dissertação & 01 & 2,13 \\
\hline Livro & 20 & 42,55 \\
\hline Tese & 01 & 2,13 \\
\hline Trabalho de Evento & 04 & 8,51 \\
\hline Total & 47 & 100,00 \\
\hline
\end{tabular}

periódicos, capítulos de livros e livro no todo, somando um percentual de $87,23 \%$. As demais fontes apresentam um percentual bastante reduzido.

Esse conjunto de indicadores bibliométricos permite considerar que a formação da análise documentária, no Grupo Temma, apresenta outros indicadores de ordem qualitativa que, de acordo com Rousseau (1998), são fundamentais à compreensão da produção científica de uma área.

A formalização da produção a partir da publicação em fontes formais de informação se constitui em um dos principais elementos, uma vez que implica a submissão destes aos pares constituintes da comunidade científica. Essa formalização se dá, principalmente, a partir da existência de conselhos editoriais e/ou consultivos que avaliam e emitem pareceres a respeito da validade e da qualidade dessa produção.

Além da questão dessa formalização, os dados analisados demonstram duas outras características importantes no processo de produção e comunicação do discurso científico, que são a maior circulação possibilitada pelos livros e o acesso a temáticas especializadas e atuais promovido pelos artigos de periódicos.

Outro elemento importante na análise da construção discursiva diz respeito ao idioma dos documentos fundantes do discurso, uma vez que este aponta a origem da obra e o posicionamento desses discursos. Nesse sentido, embora não seja objeto de maior análise neste artigo, é importante destacar que a noção da análise documentária de origem francesa é bastante diferente da visão norte-americana.

TABELA 2

\section{Idioma dos documentos-fonte}

\begin{tabular}{lccr}
\hline & Descrição & $\mathbf{f}(\mathbf{x})$ & $\mathbf{( \% )}$ \\
\hline Espanhol & 01 & & 2,13 \\
Francês & 16 & 34,04 \\
Inglês & 04 & 8,51 \\
Italiano & 01 & 2,13 \\
Português & 25 & 53,19 \\
\hline Total & 47 & 100,00 \\
\hline
\end{tabular}

Assim, segundo a tabela 2, do total de 47 documentos referenciados, 25 foram escritos em português, cuja freqüência é seguida pelos documentos escritos em francês e inglês, apresentando, respectivamente, os seguintes percentuais $53,19 \%, 34,04 \%$ e $8,51 \%$. Em análise mais detalhada a partir dos indícios aqui levantados, duas questões podem ser colocadas: o domínio de língua estrangeira e a afiliação a algum discurso específico. A evidência do primeiro elemento se daria a partir de informações sobre o domínio de línguas dos autores do discurso; o segundo, por sua vez, pode ser tomado como evidência, uma vez que a abordagem da análise documentária feita no discurso analisado tem por base os fundamentos das escolas francesas, tanto na área da biblioteconomia quanto da lingüística. Observa-se aqui o entendimento de Santos (2003), para quem, apesar de nem sempre ser possível precisar o tipo e nível de relação que existem entre trabalhos publicados, podese considerar indícios e evidências entre o trabalho analisado e os trabalhos referenciados e publicados anteriormente.

Mesmo considerando que a ordem cronológica não evidencia necessariamente a precedência e a originalidade do discurso, como destacou Foucault (2000), é fundamental entender, no seu conjunto, que a publicação (importante etapa do processo de produção e comunicação científica) dos discursos ou interdiscursos que fundamentam a formação das unidades discursivas da análise documentária, no Grupo Temma, deu-se entre as décadas de 1960 e 1980, segundo a tabela 3. Há, no entanto, uma primazia das últimas décadas sobre a primeira, que pode ser decorrente tanto do entendimento, por parte dos pesquisadores da atualidade, das discussões materializadas nessas fontes, quanto da maior facilidade de acesso por parte daqueles. $O$ importante aqui é considerar, ao menos, que, segundo Santos (2003), existe um jogo de relações entre os discursos que evidenciam a comunicação entre a razão individual e coletiva, embora pareça impossível precisar os tipos e níveis dessas relações.

Desse modo, mesmo considerando o traço característico do acúmulo do enunciado, em Foucault (2002), há de se

\section{TABELA 3}

Publicação dos documentos-fonte

\begin{tabular}{lccr}
\hline & Década & $\mathbf{f}(\mathbf{x})$ & $\mathbf{( \% )}$ \\
\hline 1960 & 04 & 8,51 \\
1970 & 21 & 44,68 \\
1980 & 22 & 46,81 \\
\hline Total & 47 & 100,00 \\
\hline
\end{tabular}


observar a importância da retomada desses discursos arquivados nas diversas memórias.

Ainda analisando os indicadores bibliométricos a partir dos elementos paratextuais, o comportamento dos autores que fundamentam a construção do discurso analisado é muito relevante para o entendimento da formação discursiva. No processo de construção do discurso cientifico, a relação entre os produtores dos discursos se torna evidente a partir da utilização de coautorias. Naturalmente que, considerando os traços característicos de raridade, exterioridade e acúmulo apontados por Foucault (2000), existe uma rede de relação entre os discursos, mas, no campo científico, essa pode se estabelecer e se evidenciar efetivamente, a partir da prática da co-autoria e do estabelecimento de uma rede de citações.

De acordo com os indicadores bibliométricos constantes da tabela 4, a relação entre os discursos a partir da coautoria se dá em um percentual muito pequeno, apenas $12,77 \%$ do universo. Isso implica, em outras palavras, que quase $90 \%$ dos discursos que atravessam o discurso analisado são de autoria individual.

Nesse contexto, não se pode esquecer as palavras de Alvarenga (1998), para quem a citação corresponde a um importante mecanismo que os autores utilizam para tecer complexas relações com os discursos anteriores, visando, sobretudo, ao aporte teórico-metodológico com fundamentos vigentes em sua área de pesquisa. Mais que isso, a autora acrescenta que essa prática confirmaria uma rede de relação com os jogos de poder e a pragmática presentes na construção da ciência.

A construção do discurso da análise documentária do Grupo Temma estabelece, na coletânea analisada, relações efetivas de intertextualidade com as fontes de informação utilizadas a partir de 66 citações, sendo que, desse universo, 72,73\% corresponde a citações indiretas, que implica uma forma relativa de extração do discursofonte e o estabelecimento de uma relação contextual com outro discurso. Esse procedimento exige a análise e a interpretação dos dois contextos para evidenciar as relações possíveis. Trata-se, portanto, de relações complexas, que só poderiam ser evidenciadas em um campo mais amplo de jogo de formações discursivas, conforme sugeriram Foucault (2000) e Santos (2003), principalmente por se encontrarem entre pontos extremos do dito ao jamais dito.

TABELA 5
TABELA 4

Autoria dos documentos-fonte

\begin{tabular}{lccr}
\hline & Tipologia & $\mathbf{f}(\mathbf{x})$ & $\mathbf{( \% )}$ \\
\hline Co-autoria & & 06 & 12,77 \\
Autoria Individual & 41 & 87,23 \\
\hline Total & & 47 & 100,00 \\
\hline
\end{tabular}

$\underline{\text { Total }}$

100,00
Citações dos documentos-fonte

\begin{tabular}{lccccccc}
\hline \multicolumn{1}{c}{ Tipologia } & Cap. & Cap. & Cap. & Cap. & Cap. & Cap. & Total \\
& $\mathbf{1}$ & $\mathbf{2}$ & $\mathbf{3}$ & $\mathbf{4}$ & $\mathbf{5}$ & $\mathbf{6}$ & \\
\hline Citação Direta & 01 & 03 & 01 & 05 & 06 & - & 16 \\
Citação Indireta & 13 & 12 & 09 & 12 & 01 & 01 & 48 \\
Citação de Citação & 02 & - & - & - & - & - & 02 \\
\hline Total & 16 & 15 & 10 & 17 & 07 & 01 & 66 \\
\hline
\end{tabular}

No que concerne ainda aos procedimentos de citação na composição das unidades do discurso analisado, é interessante observar que, exceção feita ao Capítulo 5, todos eles apresentam o percentual de citação indireta superior às somas dos demais percentuais. Além de evidenciar as relações semânticas entre o texto atual e o texto citado, como observou Alvarenga (1998), as citações colocam em jogo outras variáveis próprias da descrição arqueológica de Foucault (2000) como a dispersão e a irregularidade.

Se, por um lado, os indicadores bibliométricos paratextuais apresentam, na maioria das vezes, indícios ou, para usar as palavras de Foucault (2000), elementos de superfícies emergentes do discurso, por outro, os indicadores bibliométricos textuais possibilitam maior consolidação desses e evidenciam alguns outros elementos da formação discursiva que podem demonstrar filiações teórico-metodológicas a partir de seus contextos específicos.

Assim, no confronto e comparação entre as temáticas referenciadas e as temáticas abordadas na construção do texto da coletânea do Grupo Temma, pode-se evidenciar com maior clareza as relações estabelecidas na composição dos interdiscursos.

No que diz respeito às temáticas referenciadas, observase, de acordo com a tabela 5 , uma concentração de fontes de informação relacionadas à "Lingüística Geral" e "Leitura e Cognição", que se apresentam na ordem do discurso analisado como temáticas de fundamentação geral. Faz-se necessário destacar, no entanto, que as fontes que abordam a temática "Leitura e Cognição" foram referenciadas exclusivamente no capítulo 2 , o qual discute as estratégias de leitura no processo de análise documentária, que, de alguma forma, evidencia a ordem do seu discurso. 
TABELA 6

Documentos-fonte referenciados

\begin{tabular}{lccccccc}
\hline \multicolumn{1}{c}{ Temáticas } & Cap. & Cap. & Cap. & Cap. & Cap. & Cap. & Total \\
& $\mathbf{1}$ & $\mathbf{2}$ & $\mathbf{3}$ & $\mathbf{4}$ & $\mathbf{5}$ & $\mathbf{6}$ & \\
\hline 1 Análise & - & - & 01 & - & - & 01 & 02 \\
Documentária & & & & & & & \\
1.1 Representação & 01 & - & - & - & - & - & 01 \\
temática & & & & & & & \\
1.1.1Classificação e & 01 & - & - & - & - & - & 01 \\
indexação & & & & & & & \\
1.1.1.1 Classificação & - & - & - & - & - & - & - \\
1.1.1.1.1 Facetada & 01 & & - & - & - & - & 01 \\
1.1.1.2 Indexação & - & 01 & - & 02 & 01 & - & 04 \\
1.1.1.2.1 Tesauros & 03 & - & - & - & - & - & 03 \\
2 Inteligência Artificial & - & - & - & 01 & - & - & 01 \\
3 Epistemologia Prática & - & - & 01 & - & - & - & 01 \\
4 Lingüística Geral & - & 02 & 02 & 03 & 01 & - & 08 \\
4.1 Gramática Gerativa & - & - & 01 & - & - & - & 01 \\
4.2 Semântica & - & - & 01 & 02 & 01 & - & 04 \\
5 Análise do Discurso & - & - & 01 & 02 & & 01 & 04 \\
6 Conteúdo & - & - & - & - & 01 & - & 01 \\
7 Definições & - & - & - & - & 01 & - & 01 \\
8 Glossário & - & - & - & - & 01 & - & 01 \\
9 Semiótica & - & - & 02 & - & - & - & 02 \\
10 Leitura e Cognição & - & 08 & - & - & - & - & 08 \\
11 Imagem & - & - & - & - & - & 03 & 03 \\
11.1 Audiovisual & - & - & - & - & - & 03 & 03 \\
11.2 Fotografia & - & - & - & - & - & 04 & 04 \\
\hline Total & 06 & 11 & 09 & 10 & 06 & 12 & 54 \\
\hline
\end{tabular}

A temática "Classificação" foi acrescentada à tabela para facilitar a visualização entre as demais temáticas, sobretudo, a relação de coordenação que existe com a "Indexação", segundo o Sistema de Classificação Decimal de Dewey.

As temáticas mais relacionadas ao processo de análise documentária se apresentam como a segunda colocada na freqüência das fontes de informações referenciadas: indexação (onde se inclui o tesauros), semântica, análise do discurso e tratamento de fotografia.

A leitura da tabela 6 , a partir das temáticas abordadas na composição da coletânea do Grupo Temma, no Quadro 1, evidencia uma rede de interdiscursividade, notadamente nas temáticas de fundamentação geral, conforme destacado anteriormente, $\mathrm{e}$ naquelas mais específicas como as discussões que envolvem a análise da imagem. É justamente a partir desse jogo complexo de interdiscursividade que se estabelece a ordem do discurso da análise documentária, conforme sugeriu Foucault (2000).

Analisando os títulos dos capítulos e subcapítulos e comparando com as temáticas extraídas das fontes de

\section{QUADRO 1}

informação referenciadas, pode-se dizer que existe uma ordem ou positividade no discurso, isso significa que se pode evidenciar a formação discursiva a partir da demarcação das superfícies de emergência, da descrição de suas instâncias de delimitação, bem como da análise das grades de especificação, ou seja, das relações possíveis de se estabelecerem no campo macro do discurso, conforme apontou Foucault (2000).

Essa relação se evidencia efetivamente no último capítulo da coletânea intitulado "Revisão Bibliográfica”, no qual os autores analisam e discutem os referenciais utilizados na elaboração da publicação, que, segundo eles, constituem-se nos referenciais mais relevantes para a constituição de uma teoria da análise documentária. Acrescente-se a isso que há um procedimento lógico e coerente adotado na construção desses referenciais, partindo da lingüística geral à documentação, passando pela filosofia da linguagem, conforme se pode observar na referida revisão (SMIT, 1987).

\begin{tabular}{|c|c|}
\hline Capítulos & $\begin{array}{r}\text { Subcapítulos } \\
\end{array}$ \\
\hline \multirow[t]{3}{*}{ Linguagens de Indexação } & Linguagens Pré-coordenadas \\
\hline & Linguagens Pós-coordenadas \\
\hline & $\begin{array}{l}\text { Coordenação: Linguagens } \\
\text { coordenadas }\end{array}$ \\
\hline $\begin{array}{llll}\text { Estratégias } & \text { de } & \text { Leitura } & \text { em } \\
\text { Documentos } & & & \end{array}$ & -- \\
\hline \multirow[t]{2}{*}{ Análise Documentária } & Parâmetros Teóricos \\
\hline & Parâmetros Experimentais (metodológicos) \\
\hline \multirow[t]{4}{*}{ Estruturação de Vocabulário } & Formulação das Categorias Operacionais \\
\hline & Formação do Campo Semântico \\
\hline & Discussão dos Conceitos \\
\hline & Controle de Vocabulário: os diagramas \\
\hline \multirow{2}{*}{$\begin{array}{l}\text { A Definição Semântica para a } \\
\text { Elaboração de Glossários }\end{array}$} & Formulação de Definições \\
\hline & A Definição Semântica \\
\hline \multirow{2}{*}{$\begin{array}{l}\text { A Análise da Imagem: um primeiro } \\
\text { plano }\end{array}$} & O Documento Audiovisual é Específico? \\
\hline & $\begin{array}{l}\text { Como Analisar a Imagem para Efeito de } \\
\text { Documentação }\end{array}$ \\
\hline \multirow[t]{3}{*}{ Revisão Bibliográfica } & Lingüística Geral \\
\hline & Lógica/Filosofia da Linguagem \\
\hline & Lingüística/Documentação \\
\hline
\end{tabular}


Ainda de acordo com a autora, na estruturação do trabalho desenvolvido, notadamente na revisão bibliográfica, há forte presença de métodos de bases lógico-semânticas que foram fundamentados em trabalhos mais significativos daquelas áreas.

\section{CONSIDERAÇÕES FINAIS}

A partir das discussões empreendidas no campo teórico-metodológico e das análises e discussões dos resultados empíricos coletados, duas considerações apresentam fundamental importância: a diversidade de possibilidades de confluência de fundamentos teórico-metodológicos dos campos da bibliometria e da descrição arqueológica de Michel Foucault, e o entendimento específico da formação do discurso da análise documentária, no Grupo Temma - e por que não dizer no Brasil, já que esse grupo se apresenta como embrião das pesquisas e estudos no país -, a partir da produção científica realizada nessa área.

Concernente à confluência metodológica, considera-se que a bibliometria com seu aporte estatístico e/ou quantitativo possibilita o levantamento de uma série de elementos que indiciam o comportamento de pesquisadores, instituições, disciplinas e campos dos saber nos processos de produção e comunicação científica. Esses indícios se configuram, pois, no que Foucault (2000) denominou de elementos de superfícies emergentes do discurso. Assim, eles se apresentam como resultado de uma prática empírica que dá maior objetividade no desenvolvimento de estudos e pesquisas. Em contrapartida, as categorias apontadas por Foucault (2000), na sua descrição arqueológica, possibilitam a escansão e ampliação desses indícios em função de análises mais qualitativas e mais amplas, transformandoos em resultados ou evidências de pesquisa.

No âmbito específico da formação das unidades do discurso da análise documentária, apesar de a análise se restringir a apenas um documento do universo publicado pelo Grupo Temma, no Brasil, no decorrer dos anos, alguns indícios foram levantados e algumas evidências registradas que possibilitam algumas considerações ao seu respeito, tais como: os fundamentos desse discurso se encontram em discursos veiculados por publicações formais, notadamente, livros e artigos de periódicos, que evidenciam a submissão aos pares; há uma contribuição visível dos campos da lingüística, da leitura e da cognição, que se apresentam como temáticas que fundamentam a compreensão do processo de análise documentária e a construção de linguagens documentárias. Com relação ao estudo e à adoção da lingüística, em específico, há evidência de uma influência das escolas francesas, notadamente, no sétimo capítulo, que apresenta uma síntese da biografia dos autores e de suas respectivas obras referenciadas.

É importante ressaltar que essas relações foram todas observadas no campo da referenciação e citação, que se apresentam como a materialização da rede de relações estabelecidas na construção interdiscursiva, no âmbito da produção científica, em um sentido mais amplo, e do campo da análise documentária, em um sentido mais restrito. E, dessa forma, considera que os dados empíricos coletados e tabulados possibilitam outros tipos de análises e inferências a partir de várias combinações de análises cruzadas, tanto no nível relativo, quanto no absoluto.

Artigo submetido em 18/11/2007e aceito em 17/04/2008.

\section{AGRADECIMENTOS}

Agradecemos à professora do Programa de Pósgraduação em Ciência da Informação da Escola de Ciência da Informação da Universidade Federal de Minas Gerais doutora Lídia Alvarenga pelos ensinamentos e sugestões que contribuíram sobremaneira para a realização deste trabalho.

\section{REFERÊNCIAS}

ALVARENGA, Lídia. Bibliometria e arqueologia do saber de Michel Foucault: traços de identidade teóricometodológica. Ciência da Informação, Brasília, v. 27, n. 2, p. 253-261, maio/ago. 1998.

- Contribuições para os estudos sobre a pesquisa educacional no Brasil: análise bibliométrica de artigos da revista brasileira de estudos pedagógicos (19441974). Revista brasileira de estudos pedagógicos, Brasília, v. 81, n. 198, p. 244-272, maio/ago. 2000.

BORDONS, Maria; ZUlUETA, Maria Ángeles. Evaluación de la actividad científica a través de indicadores bibliométricos. Revista Española de Cardiologia, v. 10, out. 1999. Disponível em: < http://www.revespcardiol.org/cgibin/wdbcgi.exe/cardio/cardioeng.mrevista_ cardio.fulltext?pident =190 >. Acesso em: 20 set. 2007.

CAMPOS, Mauro. Conceitos atuais em bibliometria. Arquivo Brasileiro Oftalmologia, v. 66, p. 18-21, 2003.

CONSELHO NACIONAL DE DESENVOLVIMENTO CIENTÍFICO E TECNOLÓGICO - CNPq. Diretório dos grupos de pesquisa no Brasil: Grupo Temma. Disponível em: $<$ http://dgp.cnpq.br/buscaoperacional/ detalhegrupo.jsp?grupo $=0067607$ UVP2I76 $>$. Acesso em: 02 nov. 2007. 
FOUCAULT, Michel. Arqueologia do saber. 6. ed. Rio de Janeiro: Forense Universitária, 2000. 239 p.

GUEDES, Vânia S.; BORSCHIVER, Suzana. Bibliometria: uma ferramenta estatística para a gestão da informação e do conhecimento, em sistemas de informação, de comunicação e de avaliação científica e tecnológica. Diálogo Científico: Ciência da Informação. Disponível em: < http://dici.ibict.br/archive/00000508/01/ VaniaLSGuedes.pdf>. Acesso em: 17 jun. 2007.

INSTITUTO BRASILEIRO DE GEOGRAFIA E ESTATÍSTICA - IBGE. Normas de apresentação tabular. Rio de Janeiro: Centro de Documentação e Disseminação de Informações, 1993. Disponível em: <www.sei.ba.gov.br/ norma_tabular/normas_apresentacao_tabular.pdf $>$. Acesso em: 15 out. 2007.

LARA, Marilda Lopes Guinez de. O unicórnio (o rinoceronte, o ornitorrinco...), a análise documentária e a linguagem documentária. Data Grama Zero: revista de Ciência da Informação, v. 2, n. 6, dez. 2001. Disponível em: <http://www.dgz.org.br/dez01/Art_03.htm >. Acesso em: 15 set. 2007.

MACIAS-CHAPULA, César A. O papel da informetria e da cienciometria e sua perspeectiva nacional e internacional. Ciência da Informação, Brasília, v. 27, n. 2, p. 134-140, maio/ago. 1998.
OLIVEIRA, Cristiano de. Bibliografia do Grupo Temma na área de análise documentária e terminologia (publicações até 2005). Disponível em: <http:// infobservatorio.incubadora.fapesp.br/portal/Pub1/ Bib1/>. Acesso em: 13 set. 2007.

PRICE, Derek J. de Solla. Networks of scientific papers. Science, v. 149, n. 3683, p. 54-64, July 1965.

ROUSSEAU, Roald. Indicadores bibliométricos e econométricos para a avaliação de instituições científicas. Ciência da Informação, Brasília, v. 27, n. 2, p. 149-158, maio/ago. 1998.

SANTOS, Raimundo Nonato Macedo dos. Produção científica: por que medir?: o que medir?. Revista digital de Biblioteconomia e Ciência da Informação, Campinas, v. 1, n. 1, p. 22-38, jul./dez. 2003.

SMIT, Johanna W. (Coord). Análise documentária: a análise da síntese. Brasília: Ibict, 1987. 133 p.

VANTI, Nádia Aurora Peres. Da bibliometria à webometria: uma exploração conceitual dos mecanismos utilizados para medir o registro da informação e a difusão do conhecimento. Ciência da Informação, Brasília, v. 31, n. 2, p. 152-162, maio/ago. 2002. 